\title{
A Technique for Measuring Microparticles in Polar Ice Using Micro-Raman Spectroscopy
}

\author{
Toshimitsu Sakurai, ${ }^{1}$ Hiroshi Ohno, ${ }^{1,2}$ Shinichiro Horikawa, ${ }^{1}$ Yoshinori Iizuka, ${ }^{1}$ \\ Tsutomu Uchida, ${ }^{3}$ and Takeo Hondoh ${ }^{1}$ \\ ${ }^{1}$ Institute of Low Temperature Science, Hokkaido University, Sapporo 060-0819, Japan \\ ${ }^{2}$ Hokkaido National Industrial Research Institute, Sapporo 062-8517, Japan \\ ${ }^{3}$ Division of Applied Physics, Graduate School of Engineering, Hokkaido University, Sapporo 060-8628, Japan
}

Correspondence should be addressed to Toshimitsu Sakurai, sakurai@lowtem.hokudai.ac.jp

Received 24 May 2010; Accepted 8 July 2010

Academic Editor: Veronica Vaida

Copyright (C) 2010 Toshimitsu Sakurai et al. This is an open access article distributed under the Creative Commons Attribution License, which permits unrestricted use, distribution, and reproduction in any medium, provided the original work is properly cited.

\begin{abstract}
We describe in detail our method of measuring the chemical forms of microparticles in polar ice samples through micro-Raman spectroscopy. The method is intended for solid ice samples, an important point because melting the ice can result in dissociation, contamination, and chemical reactions prior to or during a measurement. We demonstrate the technique of measuring the chemical forms of these microparticles and show that the reference spectra of those salts expected to be common in polar ice are unambiguously detected. From our measurements, Raman intensity of sulfate salts is relatively higher than insoluble dust due to the specific Raman scattering cross-section of chemical forms of microparticles in ice.
\end{abstract}

\section{Introduction}

For the past several hundred thousand years, aerosols have been preserved as insoluble impurities (dust) and watersoluble impurities (ions) in the polar ice caps. Dust has been widely discussed as a proxy for terrestrial substances [1-3]. The concentrations of dust in melted samples from various ice cores have been measured by the Laser Scattering Method (LSM) [1] and the Coulter counter method [4]. The cited papers agree that the maximum dust input to Antarctica occurred during the last glacial maximum (the coldest event in the glacial period). The dust input was somewhat lower during stadial and interstadial periods, and lowest during interglacials and the Holocene.

The elemental compositions of dust particles in the ice core have been determined using SEM-EDS on sublimated ice samples [5], and by XRD on melted ice samples [6]. Ion concentrations can be measured either by Ion Chromatography as discussed elsewhere [7-10] or continuous flow analysis of melted samples [11]. However, the chemical forms of ice core inclusions have been a matter of debate for more than twenty years, because the ion concentrations alone do not preserve this information.

Understanding the chemical form of dust and ions present in polar ice is important to clarify the physical mechanisms behind preservation of the climate record. Some progress has been made along these lines, which we now summarize. Wolff and Paren [12] suggested that the DC conductivity of polar ice could be due to the presence of liquid layers at the grain boundaries. In agreement with this idea, SEM-EDS studies have surmised the presence of sulfuric acid at the grain boundaries in Antarctic ice [13-15], and Fukazawa et al. [16] have found evidence for sulfuric acid at the triple junction of South Yamato and Nansen ice cores, Antarctica by micro-Raman spectroscopy. Rempel et al. [17, 18] suggested that the ions exist as acid solutions (sulfuric and nitric acid) displaced by premelting and anomalous diffusion through the vein network. Lately, study from Dome Fuji ice core, Antarctica have found ions as sulfate and nitrate salts in microparticles measured by micro-Raman spectroscopy [19]. Following this result, a number of other reports [20-25] have directly 


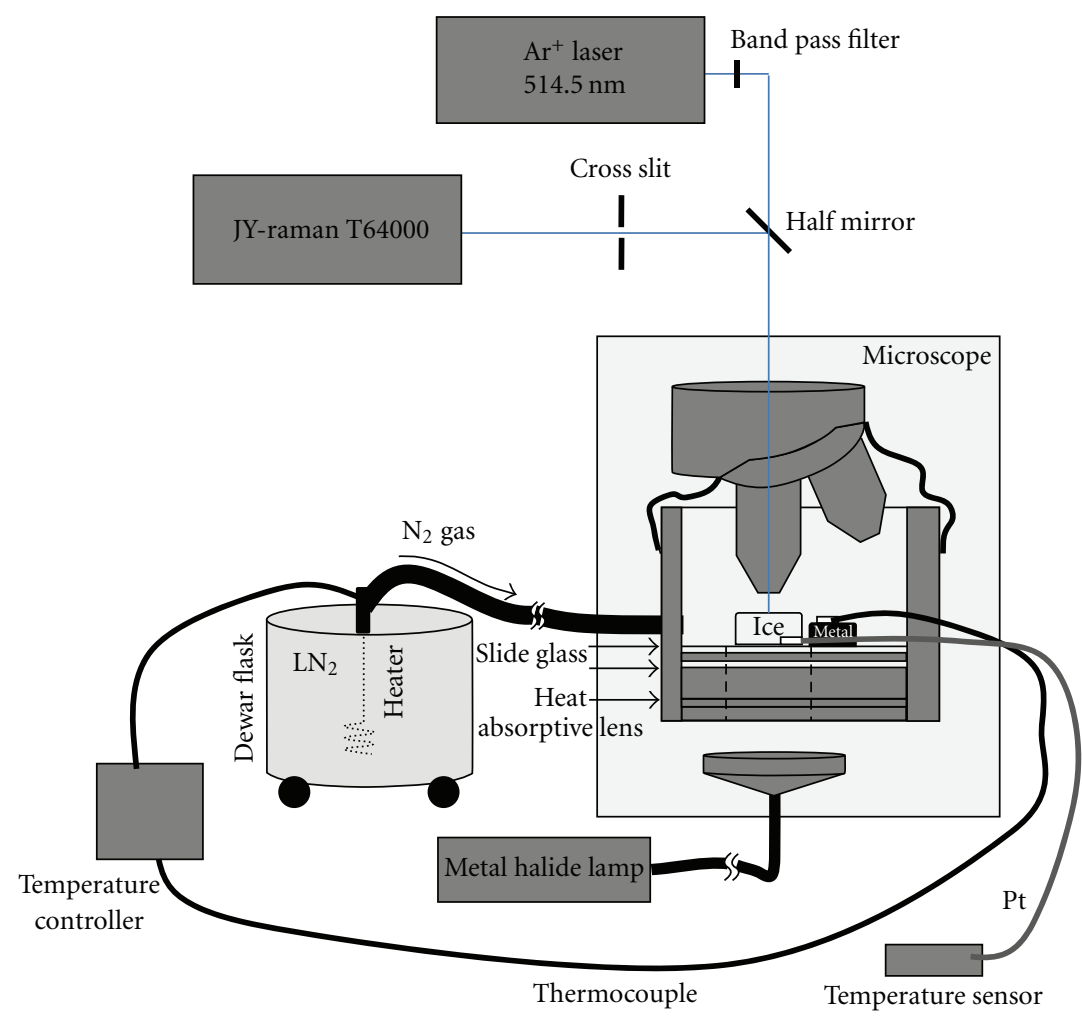

FIGURE 1: Schematic of the cryostat system. The temperature is controlled by $\mathrm{N}_{2}$ gas, evaporated by a heater inside a Dewar flask containing liquid $\mathrm{N}_{2}$. The heater is controlled by and connected to a thermocouple inside the cryostat. The cryostat container is made of chloroethene, and a Styrofoam setting is inside the container. Heat-absorptive lens and slide glasses are set inside the Styrofoam between the ice sample and the halogen light source, to prevent the latter from warming the sample.

measured the chemical forms of microparticles using the same method.

This paper reports our procedure to determine the chemical form of microparticles in polar ice through microRaman spectroscopy. Following a brief review of the technique, we will describe our methodology in detail and the importance of settings such as slit width and laser power to how we measure the microparticles. We also provide reference Raman spectra for the most common salts which can be assumed the exist in ice sheets.

\section{Setup of Cryostat}

To measure the chemical forms of the microparticles, we use a micro-Raman spectroscope and a cryostat (Figure 1). The cryostat is set on an $x-y-z$ translation stage. A thermocouple is connected to the cryostat with metal to stabilize and measure the interior temperature. Copper is used for the connection because its thermal conductivity $\left(4.01 \mathrm{~W} \mathrm{~cm}^{-1} \mathrm{~K}^{-1}\right)$ is greater than that of ice $\left(0.02 \mathrm{~W} \mathrm{~cm}^{-1} \mathrm{~K}^{-1}\right)$ [25]; the metal rapidly equilibrates to the temperature inside the cryostat. In addition to the thermocouple, we place a platinum resistance temperature sensor $(100 \Omega)$ by the sample to measure its temperature directly.

To cool the cryostat, we used an $\mathrm{N}_{2}$ gas flow from liquid nitrogen heated by a sheath coil inside the Dewar.

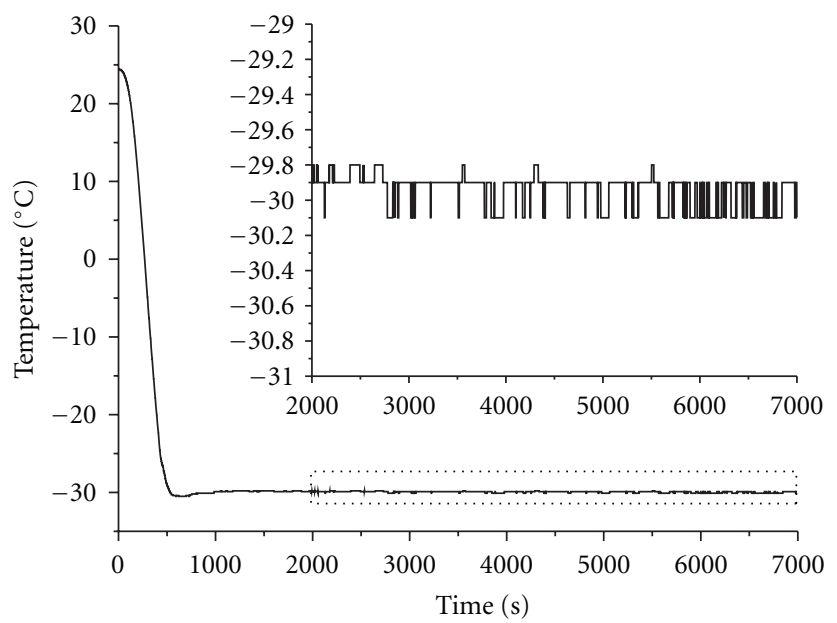

FIgure 2: Cooling the cryostat. The temperature is reduced from room temperature to a stable value of $-30.0^{\circ} \mathrm{C}$. The controller uses the auto PID method.

The sheath heater coil emits $400 \mathrm{~W}$ and has a resistance of $25.0 \Omega$. The coil is connected to a PID (proportionalintegral-derivative) temperature controller, which monitors the inside of the cryostat via the thermocouple. Figure 2 shows the temperature of the cryostat as it is cooled from room temperature to $-30.0^{\circ} \mathrm{C}$ using the PID temperature 
controller. After a cool-down phase, the cryostat can be maintained at constant temperature for a long period with no significant gradient in the ice sample. Laser light cannot irradiate the microparticles during this phase. To stabilize the temperature at $-30.0^{\circ} \mathrm{C} \pm 0.2^{\circ} \mathrm{C}$ it took about 30 minutes for our cryostat.

\section{Raman Spectroscopy}

We employed an Ar ion laser with a wavelength of $514.5 \mathrm{~nm}$ (NEC GLG3260) and a maximum beam power of $1000 \mathrm{~mW}$ at the source. A band pass filter (Edmund Optics 47492-J) is placed just after the laser source. The filter blocks $99.995 \%$ of wavelengths in the ranges $434-509 \mathrm{~nm}$ and $520-670 \mathrm{~nm}$ (its optical density in this range is better than 5.0) and brocks only $10 \%$ of the central wavelength. We verified that the attenuation of the laser was independent of its power at the source by measuring the laser power at the objective lens for several different intensity settings. The laser power at the objective lens is always about $10 \%$ of the source power due to optical loss in the optical system in the equipment.

To detect the Raman spectra, it is necessary to focus the laser on a microparticle through a high-magnification objective lens. However, the focal lengths of such lenses are generally small. In the cryostat, the ice sample has to be kept at a stable temperature so that microparticles and the ice section itself do not move during the measurement. Therefore, managing the heat flux from the objective lens to the ice sample is a significant problem. To avoid creating a temperature gradient between the objective lens and the sample, we chose an objective lens with a super-long working distance $(6.0 \mathrm{~mm}$ focal length) and a numerical aperture (N.A.) of 0.75 (Mitutoyo, M Plan Apo 100x). Please note that the temperature increases of ice during emitting the laser inside of the ice are not confirmed but some chemical form could be.

We use a triple monochromator (Jobin-Yvon, T64000) and a CCD detector (Jobin-Yvon, Spectraview-2D, $1024 \times$ 256 pixels, cooled by liquid nitrogen) with good quantum efficiency from 500 to $900 \mathrm{~nm}$. Using a grating with 1800 lines $/ \mathrm{mm}$ and an entrance slit of $100 \mu \mathrm{m}$, the spectral resolution between two points is $0.6 \mathrm{~cm}^{-1}$. The absolute frequency of the monochromator was calibrated using a neon emission line and silicon wafers.

The cross slit is the one of the most important components to measure the microparticles in ice by microRaman spectroscopy. It allows the researcher to change the size of the cross slit, from several micrometers down to 1 micrometer. The smallest cross slit results in a low-intensity peak compared to the large cross slits, but all settings greater than $5.0 \mu \mathrm{m}$ yield nearly the same intensity. The variation in peak intensity will be significant when we discuss the measurement of micron-sized particles in ice.

\section{Reference Samples}

To identify the chemical forms of microparticles in ice cores, we need to know the spectra of the chemicals in advance. A database of reference spectra for various minerals, both water-soluble and insoluble, is available at the RRUFF website (http://rruff.info/) among others. However, Raman spectra of some salts are not measured. Thus, to compare the spectra of salt groups, we measured reference spectra for the following specimens: $\mathrm{Na}_{2} \mathrm{SO}_{4}$ (thenardite), $\mathrm{Na}_{2} \mathrm{SO}_{4} \cdot 7 \mathrm{H}_{2} \mathrm{O}, \mathrm{Na}_{2} \mathrm{SO}_{4} \cdot 10 \mathrm{H}_{2} \mathrm{O}$ (mirabilite), $\mathrm{NaHSO}_{4} \cdot \mathrm{H}_{2} \mathrm{O}, \mathrm{MgSO}_{4} \cdot 7 \mathrm{H}_{2} \mathrm{O}$ (epsomite), $\mathrm{MgSO}_{4} \cdot 11 \mathrm{H}_{2} \mathrm{O}$ (meridianiite), $\mathrm{CaSO}_{4} \cdot 2 \mathrm{H}_{2} \mathrm{O}$ (gypsum), $\mathrm{CaSO}_{4} \cdot 0.5 \mathrm{H}_{2} \mathrm{O}$, (NH4) ${ }_{2} \mathrm{SO}_{4}$ (mascagnite), $\mathrm{NaCl} \cdot 2 \mathrm{H}_{2} \mathrm{O}$ (hydrohalite), $\mathrm{MgCl}_{2} \cdot 6 \mathrm{H}_{2} \mathrm{O}, \mathrm{MgCl}_{2} \cdot 12 \mathrm{H}_{2} \mathrm{O}, \mathrm{NaNO}_{3}, \mathrm{Mg}\left(\mathrm{NO}_{3}\right)_{2} \cdot 6 \mathrm{H}_{2} \mathrm{O}$, $\mathrm{Ca}\left(\mathrm{NO}_{3}\right)_{2} \cdot 4 \mathrm{H}_{2} \mathrm{O}, \quad \mathrm{NH}_{4} \mathrm{NO}_{3}, \quad \mathrm{Na}_{2} \mathrm{CO}_{3}, \quad \mathrm{Na}_{2} \mathrm{CO}_{3} \cdot 10 \mathrm{H}_{2} \mathrm{O}$, $\mathrm{CaCO}_{3}, \quad \mathrm{CH}_{3} \mathrm{SO}_{3} \mathrm{Na} \cdot n \mathrm{H}_{2} \mathrm{O}, \quad\left(\mathrm{CH}_{3} \mathrm{SO}_{3}\right)_{2} \mathrm{Mg} \cdot n \mathrm{H}_{2} \mathrm{O}$, $\mathrm{CH}_{3} \mathrm{SO}_{3} \mathrm{~K} \cdot n \mathrm{H} 2 \mathrm{O}$, and $\left(\mathrm{CH}_{3} \mathrm{SO}_{3}\right)_{2} \mathrm{Ca} \cdot n \mathrm{H}_{2} \mathrm{O}$. It is necessary to measure these salts below their eutectic temperatures, which can be determined by constructing a phase diagram which discussed elsewhere [26-28]. In this paper, the number of hydrates written in each chemical forms are from phase diagrams of previous studies. For instance, number of hydrates of $\mathrm{MgSO}_{4}$ is assumed to be $12 \mathrm{H}_{2} \mathrm{O}$ for more than a century, but surprisingly Genceli et al. [29] found number of hydrates of $\mathrm{MgSO}_{4}$ as $11 \mathrm{H}_{2} \mathrm{O}$. The reference Raman spectra of groups $\mathrm{SO}_{4}^{2-}, \mathrm{Cl}^{-}, \mathrm{NO}_{3}^{-}, \mathrm{CO}_{3}^{2-}$, and $\mathrm{CH}_{3} \mathrm{SO}_{3}^{-}$ are shown in Supplementary Material available online at doi:10.1155/2010/384956.

\section{Ice Preparation}

Ice sections are cut from the Termination I (climate change during LGM to Holocene) of Dome Fuji ice core and planed by microtome to a thickness of several millimeters. To fit inside the cryostat, we usually cut the planed samples down to $50 \times 30 \times$ thickness $\mathrm{mm}^{3}$. The thickness depends on the grain size of the ice section. If the ice crystals are smaller than the sample thickness, the laser may reflect at a grain boundary and prevent us from clearly seeing the microparticles. Ideally, for the microparticles to be clearly visible, the sample thickness should be approximately equal to the ice grain size.

Several minutes after the sample is placed in the cryostat, the temperature has stabilized. The ice is backlit by a metal halide lamp, and we use a low-magnification lens (focal length $33.5 \mathrm{~mm}$ and N.A. 0.28; Mitsutoyo M Plan Apo 10x) to search for microparticles. When we find one, we focus the laser on the microparticle with the 100x lens and record its Raman spectrum.

\section{Measuring Microparticles in Polar Ice}

To measure microparticles of various diameters in polar ice by micro-Raman spectroscopy, it is necessary to take several parameters into account. The two most important considerations are the width of the cross slit and the power of the laser.

We measured microparticles approximately $3.0 \mu \mathrm{m}$ in diameter to show how the Raman signal changes with cross slit width and laser power. Figure 3 shows the dependence of peak intensity on slit width for single microparticles in 


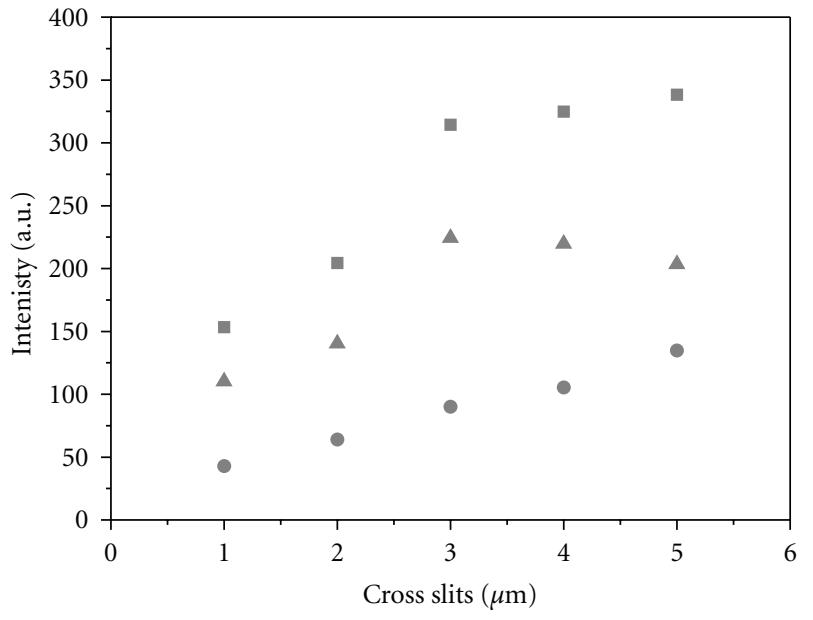

- Raman spectra of ice and microparticles

- Base line of ice

$\Delta$ Microparticles

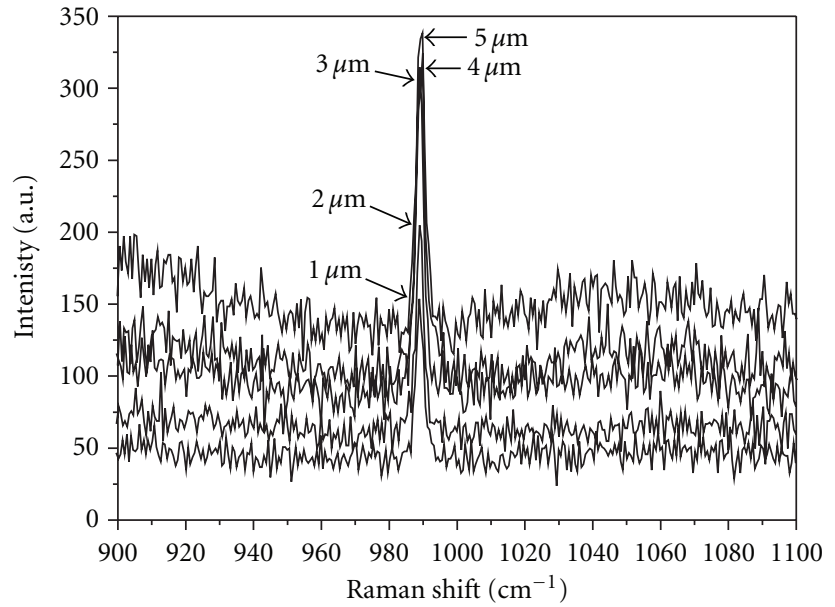

(b)

FIgURE 3: The plotted intensities are Raman peaks from the S-O symmetric stretching mode of a mirabilite microparticle found in the Dome Fuji ice core, for several cross slit widths. The left-hand plot (a) shows the peak intensities as a function of slit width. The series "Raman spectra of ice and microparticles" is derived from the raw spectral data. "Baseline of ice" is an average of 60 spectra taken from points on the ice without any microparticles. This spectrum is subtracted from the raw spectra of the S-O symmetric stretching mode to obtain the "Microparticle" spectrum. The right-hand plot (b) shows the raw data of each spectra.

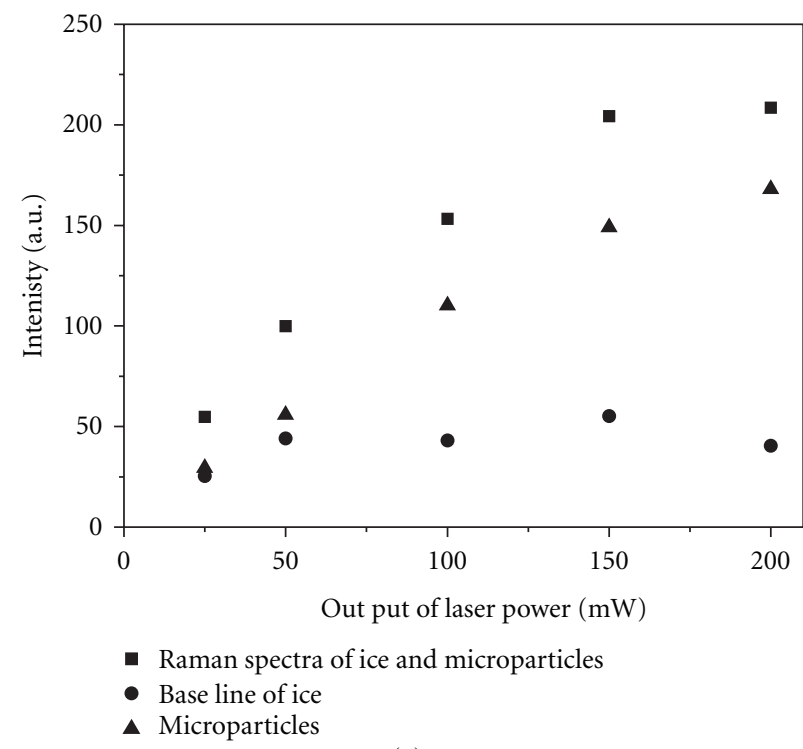

(a)

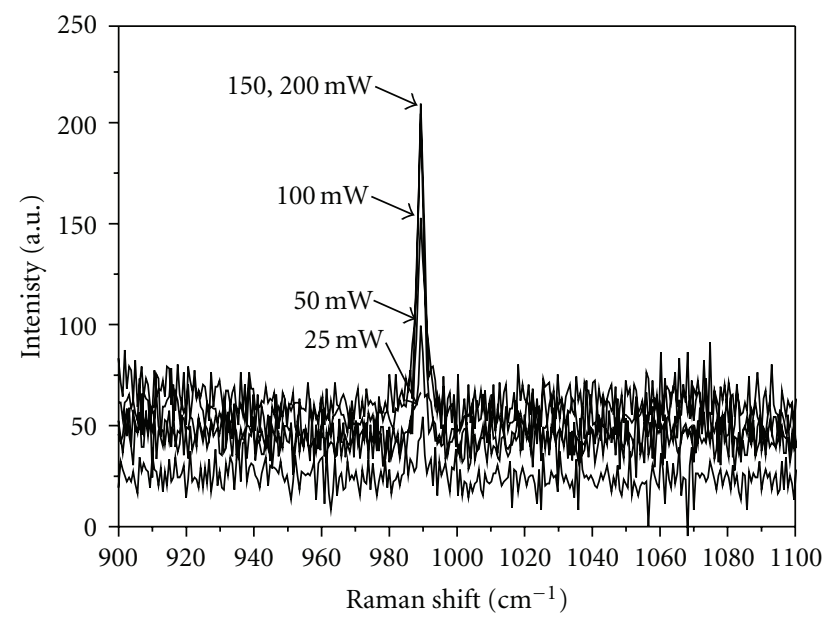

(b)

FIGURE 4: As Figure 3, expect that the intensities of the S-O symmetric stretching mode are measured for several different laser powers.

Dome Fuji ice with the laser power set to $100 \mathrm{~mW}$ and a total measuring time of 120 seconds. The Raman intensity of the microparticles alone, obtained by subtracting the spectrum of the ice, increases with slit width up to $3.0 \mu \mathrm{m}$ then decreases gradually for greater widths. Figure 4 compares the spectra of $\mathrm{Na}_{2} \mathrm{SO}_{4} \cdot 10 \mathrm{H}_{2} \mathrm{O}$ (mirabilite) microparticles in ice with the cross slit set to $1.0 \mu \mathrm{m}$, for five different values of the laser power. The intensities obtained rise with the laser power, but beyond $200 \mathrm{~mW}$ do not change significantly (data in this range are omitted from the figure). Taken together, these results suggest that the cross slit should be the same size as the microparticles.

Here we show the example of the result from Termination I, Dome Fuji ice core. Figure 5 shows the result where microparticles were analyzed using a laser power of $200 \mathrm{~mW}$. A total number of microparticles are 758 particles 


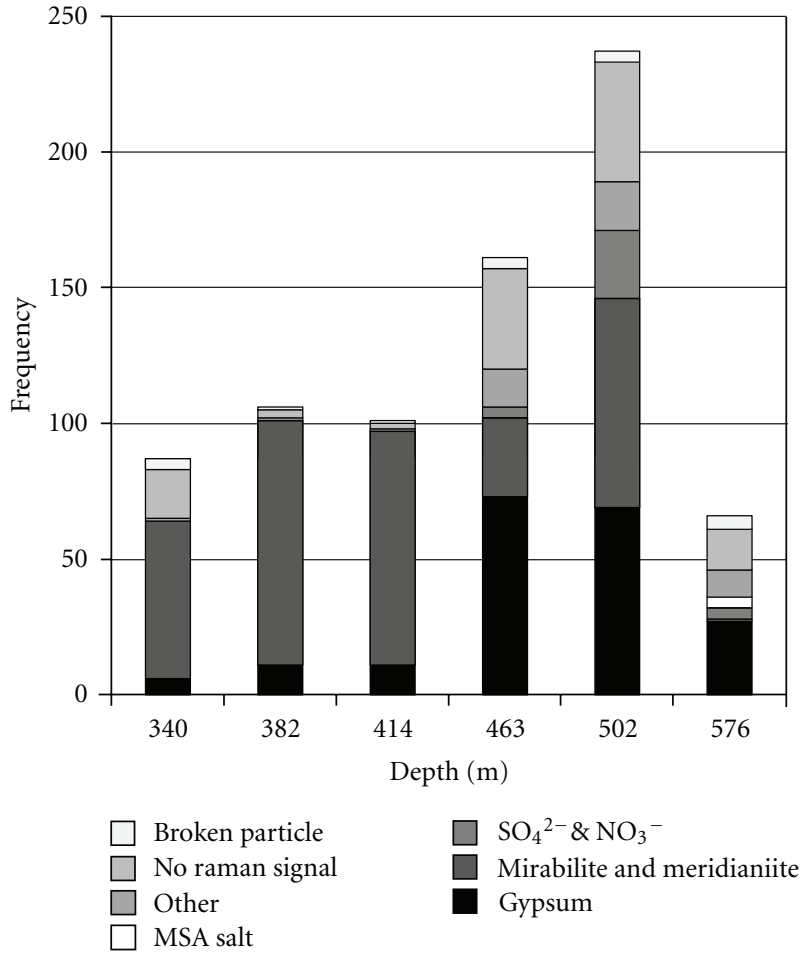

FIgURE 5: The distribution of microparticle chemical forms found in ice samples taken from Termination I of the Dome Fuji ice core. 340 m: Holocene, 382-502 m: Termination I, $576 \mathrm{~m}$ : Last Glacial Maximum. The numbers of microparticles measured at each depth are $87,106,101,161,237$, and 66 , respectively, (a total of 758 particles). The numbers of microparticles in the "no Raman signal" category are $18,3,2,37,44$, and 15 , respectively. The numbers of "broken particles" are 4, 1, 1, 4, 4, and 5, respectively.

include the particle which has the double peaks. For instance, in the case of the spectra from one microparticle include $\mathrm{CaSO}_{4} \cdot 2 \mathrm{H}_{2} \mathrm{O}$ (gypsum) and $\mathrm{Na}_{2} \mathrm{SO}_{4} \cdot 10 \mathrm{H}_{2} \mathrm{O}$ (mirabilite), then we count two microparticles for the frequency. We found $\mathrm{CaSO}_{4} \cdot 2 \mathrm{H}_{2} \mathrm{O}$ (gypsum), $\mathrm{Na}_{2} \mathrm{SO}_{4} \cdot 10 \mathrm{H}_{2} \mathrm{O}$ (mirabilite), $\mathrm{MgSO}_{4} \cdot 11 \mathrm{H}_{2} \mathrm{O}$ (meridianiite), nitrate with sulfate, methanesulfonate salt, and another chemical forms which we have not yet identified which are classified as "others". However, there are still some difficulties to be resolved with this method of analyzing microparticles in polar ice. For instance, some microparticles either give Raman signals too weak to be detected or are composed of Raman-inactive materials. These are classified as "no Raman signal". A few microparticles changed shape when we compare their images before and after Raman spectroscopy, so they are classified as "broken particles". These particles probably melted and/or broke apart during measurement due to the high laser power. Thus, we are still unable to measure the chemical form of all microparticles in polar ice, but we insist that the method is very successful and reliable for certain chemical forms. It is especially useful for measuring sulfates $\left(\mathrm{CaSO}_{4} \cdot 2 \mathrm{H}_{2} \mathrm{O}, \mathrm{Na}_{2} \mathrm{SO}_{4} \cdot 10 \mathrm{H}_{2} \mathrm{O}\right.$, $\mathrm{MgSO}_{4} \cdot 11 \mathrm{H}_{2} \mathrm{O}$ ), which are relatively abundant compared to other types of microparticles in polar ice. Please note

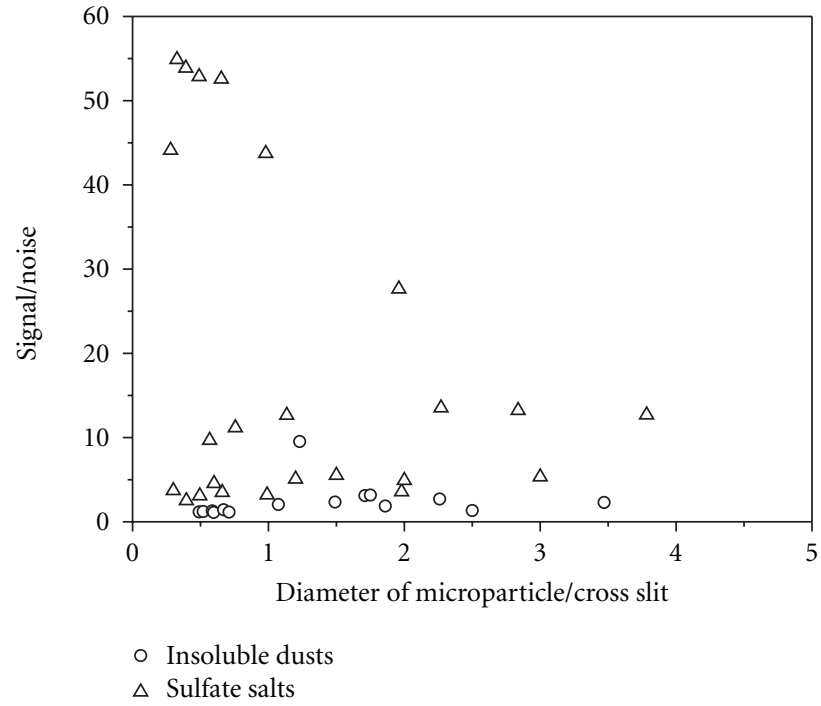

FIGURE 6: The signal-to-noise ratios of the Raman spectra are plotted against the ratio of particle diameter to cross slit width. Sulfate salts yield very intense Raman spectra compared to dust, even though the particles are small.

that to perfectly distinguish the similar Raman spectra of $\mathrm{Na}_{2} \mathrm{SO}_{4} \cdot 10 \mathrm{H}_{2} \mathrm{O}$ and $\mathrm{MgSO}_{4} \cdot 11 \mathrm{H}_{2} \mathrm{O}$, we have to measure the spectrum by higher resolution [19].

An additional factor is the ratio between the width of the slit and the diameter of the microparticle. Figure 6 shows the relation of intensity of microparticles and diameter divided by cross slit. Raman intensity of sulfate salts is relatively higher than insoluble dust due to the specific Raman scattering cross section of chemical forms and insoluble dusts may contain several components including Raman inactive chemicals. Thus, to measure the insoluble dust by this method, we have to identify the chemical form of dusts with the several peaks (more than one peak) of Raman scattering from dusts. For instance, the $\mathrm{NaAlSi}_{3} \mathrm{O}_{8}$ (albite) has several peaks that include weaker ones [30]. If these peaks corresponded well, then we surly identified the chemical form of mineral dust. If whole peaks did not correspond well, then the microparticles cannot be identified.

The theoretical cross-sections of microparticles have previously been described in detail by various aerosol studies [31-33]. The radiant flux $\Phi$ scattered into a solid angle $\Omega$ from a single microparticle $P$ with composition $A$ given by

$$
\Phi_{P, A}=\varphi_{0} c_{A} N_{a} V_{P} \cdot \int_{\Omega_{0}} r_{A}\left(\lambda_{0}, \lambda_{s}\right) \cdot p(n, x, \Theta) \mathrm{d} \Omega,
$$

where $\varphi_{0}$ is the radiant flux density of the incident laser beam, $c_{A}$ is the molar concentration of composition $A, N_{a}$ is Avogadro's constant, and $V_{P}$ is the volume of the microparticle. The Raman scattering cross-section $r_{A}$, included within the integral, depends on the incident wavelength $\lambda_{0}$ and Raman wavelength $\lambda_{s}$, but is independent of the microparticle's morphology. The morphology factor $p$ is dependent on the refractive index $n$, the size $x$ and the scattering angle $\Theta$. To understand the relationship between our quantitative Raman 
spectroscopic measurements and these parameters, it is necessary to understand the morphology of the microparticles. This is especially true for sulfates, which would not fully understand the refractive index of salts (e.g., $\mathrm{Na}_{2} \mathrm{SO}_{4} \cdot 10 \mathrm{H}_{2} \mathrm{O}$, $\left.\mathrm{MgSO}_{4} \cdot 11 \mathrm{H}_{2} \mathrm{O}, \mathrm{CaSO}_{4} \cdot 2 \mathrm{H}_{2} \mathrm{O}\right)$. Further experimental work on the refractive indices and scattering angle of several salts is needed, not just to estimate the parameter $p$ but also to clarify the most suitable wavelength of laser light to use for measuring specific microparticles (including dust) in ice by Raman spectroscopy. Continued research in this view would aid in future measurements of microparticles and help researchers understand the process of radiative forcing on aerosols in past atmospheric conditions corresponding to the glacial and interglacial cycle.

\section{Acknowledgments}

We thank Drs. A. Hori and A. Miyamoto for valuable discussions, as well as the Dome Fuji drilling team. We also thank K. Shinbori and M. Ikeda of the Institute of Low Temperature Science at Hokkaido University for designing and constructing the cryostat for micro Raman spectroscopy. We would like to thank Scientific Editor V. Vaida for handling the paper. This study was supported by Grant-in-Aid for Creative Scientific Research (Grant nos. 14GS0202 and 21710002) and by the Global COE Program (Establishment of Center for Integrated Field Environmental Science). Funding was also provided by the Japan Ministry of Education, Culture, Sports, Science and Technology (MEXT) and the Japan Society for the Promotion of Science (JSPS).

\section{References}

[1] Y. Fujii, M. Kohno, S. Matoba, H. Motoyama, and O. Watanabe, "A 320 k-year record of microparticles in the Dome Fuji, Antarctica ice core measured by laser-light scattering," Memoirs of National Institute of Polar Research, vol. 57, pp. 4662, 2003.

[2] E. W. Wolff, H. Fischer, F. Fundel et al., "Southern Ocean seaice extent, productivity and iron flux over the past eight glacial cycles," Nature, vol. 440, no. 7083, pp. 491-496, 2006.

[3] F. Lambert, B. Delmonte, J. R. Petit et al., "Dust-climate couplings over the past 800,000 years from the EPICA Dome C ice core," Nature, vol. 452, no. 7187, pp. 616-619, 2008.

[4] B. Delmonte, J. Petit, and V. Maggi, "Glacial to Holocene implications of the new 27000-year dust record from the EPICA Dome C (East Antarctica) ice core," Climate Dynamics, vol. 18, no. 8, pp. 647-660, 2002.

[5] P. R. F. Barnes, R. Mulvaney, E. W. Wolff, and K. Robinson, "A technique for the examination of polar ice using the scanning electron microscope," Journal of Microscopy, vol. 205, no. 2, pp. 118-124, 2002.

[6] A. Svensson, P. E. Biscaye, and F. E. Grousset, "Characterization of late glacial continental dust in the Greenland Ice Core Project ice core," Journal of Geophysical Research D, vol. 105, no. 4, pp. 4637-4656, 2000.

[7] M. Legrand, M. de Angelis, and F. Maupetit, "Field investigation of major and minor ions along summit (Central Greenland) ice cores by ion chromatography," Journal of Chromatography, vol. 640, no. 1-2, pp. 251-258, 1993.
[8] Y. Iizuka, M. Takata, T. Hondoh, and Y. Fujii, "High-timeresolution profiles of soluble ions in the last glacial period of a Dome Fuji (Antarctica) deep ice core," Annals of Glaciology, vol. 39, pp. 452-456, 2005.

[9] Y. Iizuka, T. Hondoh, and Y. Fujii, " $\mathrm{Na}_{2} \mathrm{SO}_{4}$ and $\mathrm{MgSO}_{4}$ salts during the Holocene period derived by high-resolution depth analysis of a Dome Fuji ice core," Journal of Glaciology, vol. 52, no. 176, pp. 58-64, 2006.

[10] Y. Iizuka, T. Hondoh, and Y. Fujii, "Antarctic sea ice extent during the Holocene reconstructed from inland ice core evidence," Journal of Geophysical Research D, vol. 113, no. 15, Article ID D15114, 2008.

[11] R. Röthlisberger, M. Bigler, M. Hutterli et al., "Technique for continuous high-resolution analysis of trace substances in firn and ice cores," Environmental Science and Technology, vol. 34, no. 2, pp. 338-342, 2000.

[12] E. W. Wolff and J. G. Paren, "A two-phase model of electrical conduction in polar ice sheets," Journal of Geophysical Research, vol. 89, no. 11, pp. 9433-9438, 1984.

[13] R. Mulvaney, K. Oates, and E. W. Wolff, "Sulphuric acid at grain boundaries in Antarctic ice," Nature, vol. 331, no. 6153, pp. 247-249, 1988.

[14] P. R. F. Barnes, R. Mulvaney, E. W. Wolff, and K. Robinson, "A technique for the examination of polar ice using the scanning electron microscope," Journal of Microscopy, vol. 205, no. 2, pp. 118-124, 2002.

[15] I. Baker and D. Cullen, "SEM/EDS observations of impurities in polar ice: artifacts or not?" Journal of Glaciology, vol. 49, no. 165, pp. 184-190, 2003.

[16] H. Fukazawa, K. Sugiyama, S. Mae, H. Narita, and T. Hondoh, "Acid ions at triple junction of Antarctic ice observed by Raman scattering," Geophysical Research Letters, vol. 25, no. 15, pp. 2845-2848, 1998.

[17] A. W. Rempel, E. D. Waddington, J. S. Wettlaufer, and M. G. Worster, "Possible displacement of the climate signal in ancient ice by premelting and anomalous diffusion," Nature, vol. 411, no. 6837, pp. 568-571, 2001.

[18] A. W. Rempel, J. S. Wettlaufer, and E. D. Waddington, "Anomalous diffusion of multiple impurity species: predicted implications for the ice core climate records," Journal of Geophysical Research B, vol. 107, no. 12, pp. 1-12, 2002.

[19] H. Ohno, M. Igarashi, and T. Hondoh, "Salt inclusions in polar ice core: location and chemical form of water-soluble impurities," Earth and Planetary Science Letters, vol. 232, no. 1-2, pp. 171-178, 2005.

[20] H. Ohno, M. Igarashi, and T. Hondoh, "Characteristics of salt inclusions in polar ice from Dome Fuji, East Antarctica," Geophysical Research Letters, vol. 33, no. 8, Article ID L08501, 2006.

[21] Y. Iizuka, S. Horikawa, T. Sakurai et al., "A relationship between ion balance and the chemical compounds of salt inclusions found in the Greenland Ice Core Project and Dome Fuji ice cores," Journal of Geophysical Research D, vol. 113, no. 7, Article ID D07303, 2008.

[22] Y. Iizuka, T. Miyake, M. Hirabayashi et al., "Constituent elements of insoluble and non-volatile particles during the Last Glacial Maximum exhibited in the Dome Fuji (Antarctica) ice core," Journal of Glaciology, vol. 55, no. 191, pp. 552-562, 2009.

[23] F. E. Genceli, S. Horikawa, Y. Iizuka et al., "Meridianiite detected in ice," Journal of Glaciology, vol. 55, no. 189, pp. 117122, 2009.

[24] T. Sakurai, Y. Ilzuka, S. Horlkawa et al., "Direct observation of salts as micro-inclusions in the Greenland GRIP ice core," Journal of Glaciology, vol. 55, no. 193, pp. 777-783, 2009. 
[25] D. R. Lide, Ed., CRC Handbook of Chemistry and Physics, CRC Press, Boca Raton, Fla, USA, 81st edition, 2000-2001.

[26] E. Usdowski and M. Dietzel, Atlas and Data of Solid-Solution Equilibria of Marine Evaporites, Springer, Berlin, Germany, 1998.

[27] W. F. Linke, Solubilities: Inorganic and Metal-Organic Compounds, A-Ir, vol. 1, American Chemical Society, Washington, DC, USA, 4th edition, 1958.

[28] W. F. Linke, Solubilities: Inorganic and Metal-Organic Compounds, $K-Z$, vol. 2, American Chemical Society, Washington, DC, USA, 4th edition, 1965.

[29] F. E. Genceli, M. Lutz, A. L. Spek, and G.-J. Witkamp, "Crystallization and characterization of a new magnesium sulfate hydrate $\mathrm{MgSO}_{4} \cdot 11 \mathrm{H}_{2} \mathrm{O}$," Crystal Growth and Design, vol. 7, no. 12, pp. 2460-2466, 2007.

[30] T. Sakurai, Y. Iizuka, S. Horikawa, T. Uchida, and T. Hondoh, "Finding of sulfate salt as liquid microparticles in Dome Fuji ice core, Antarctica," submitted to Earth and Planetary Science Letters.

[31] G. Schweiger, "In-situ determination of the molecular composition of aerosol particles in a monodisperse model aerosol," Particle Characterization, vol. 4, no. 2, pp. 67-73, 1987.

[32] G. Schweiger, "Raman scattering on microparticles: size dependence," Journal of the Optical Society of America B, vol. 8, no. 8, pp. 1770-1778, 1991.

[33] R. Vehring, H. Moritz, D. Niekamp, G. Schweiger, and P. Heinrich, "Linear Raman spectroscopy on droplet chains: a new experimental method for the analysis of fast transport processes and reactions on microparticles," Applied Spectroscopy, vol. 49, no. 9, pp. 1215-1224, 1995. 


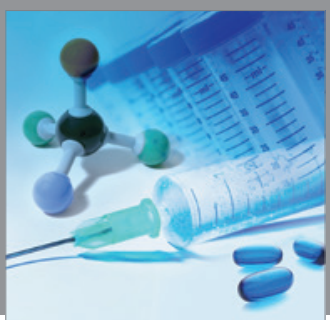

International Journal of

Medicinal Chemistry

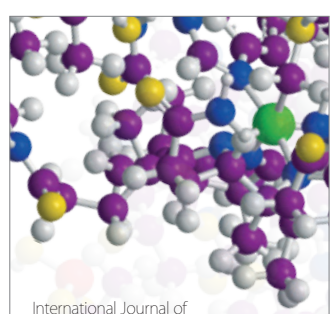

Carbohydrate Chemistry

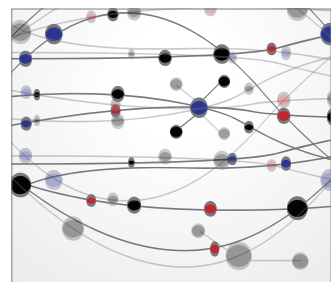

The Scientific World Journal
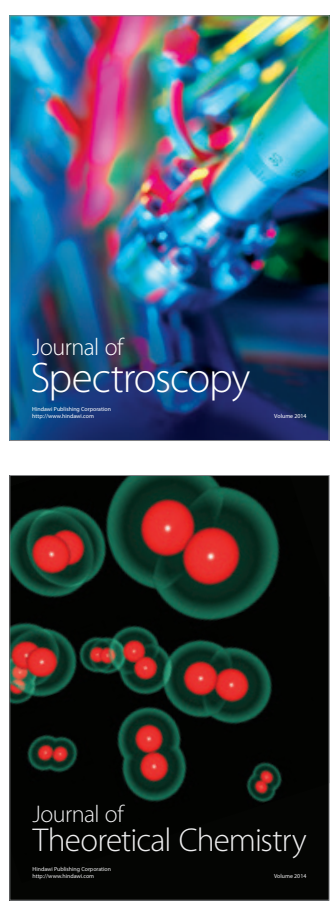
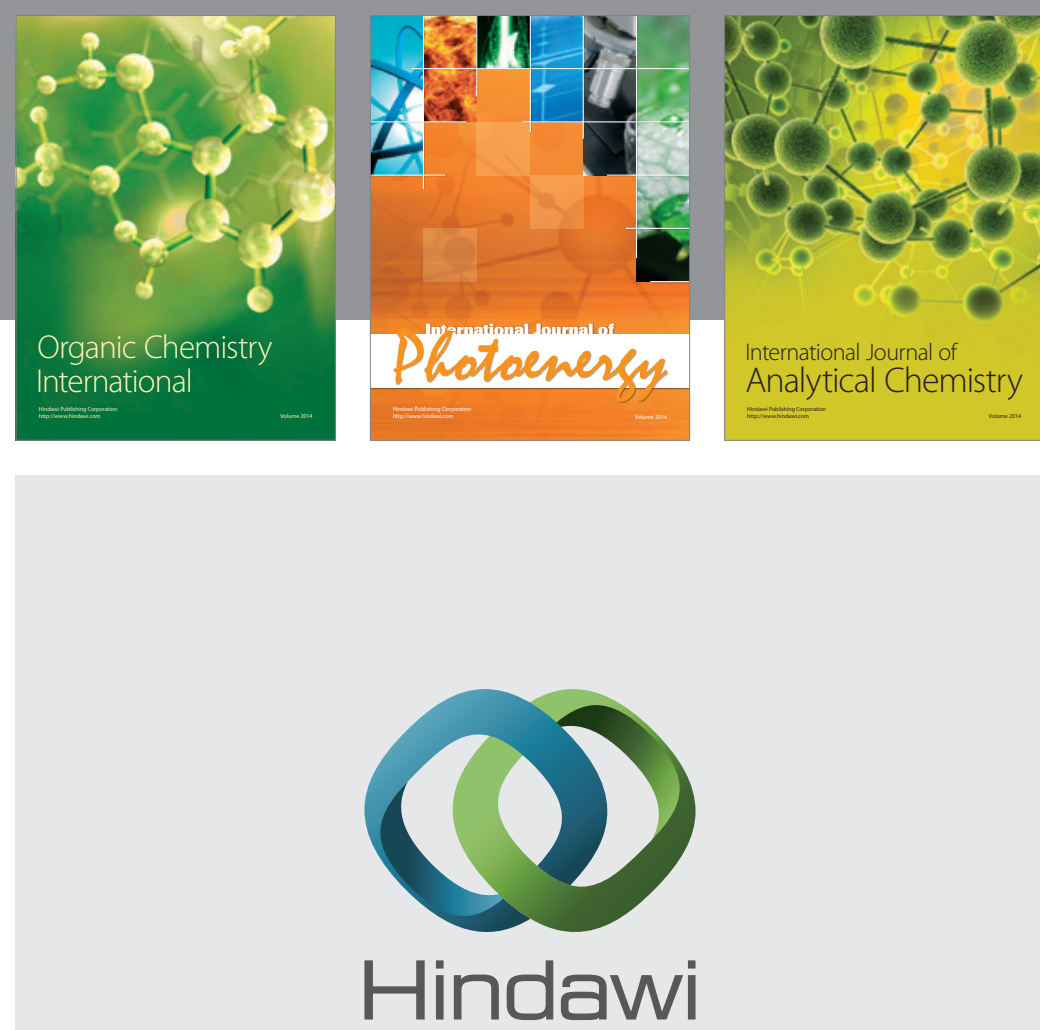

Submit your manuscripts at

http://www.hindawi.com
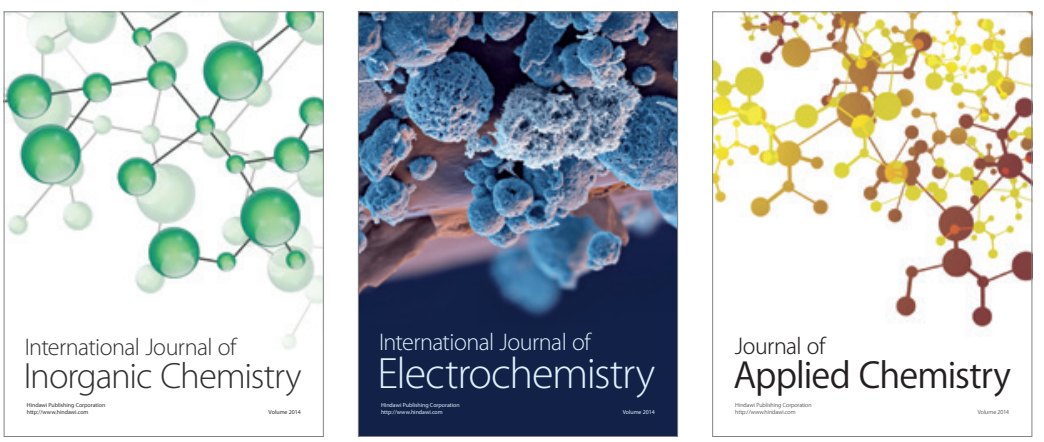

Journal of

Applied Chemistry
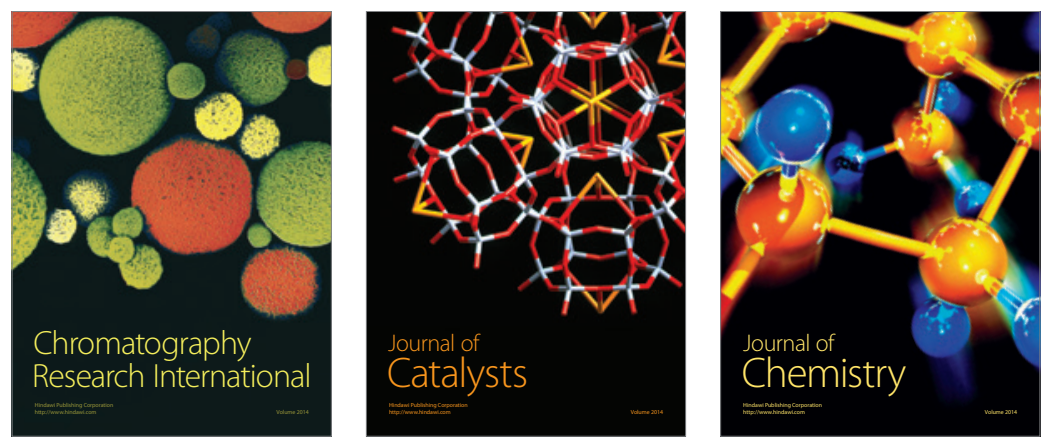
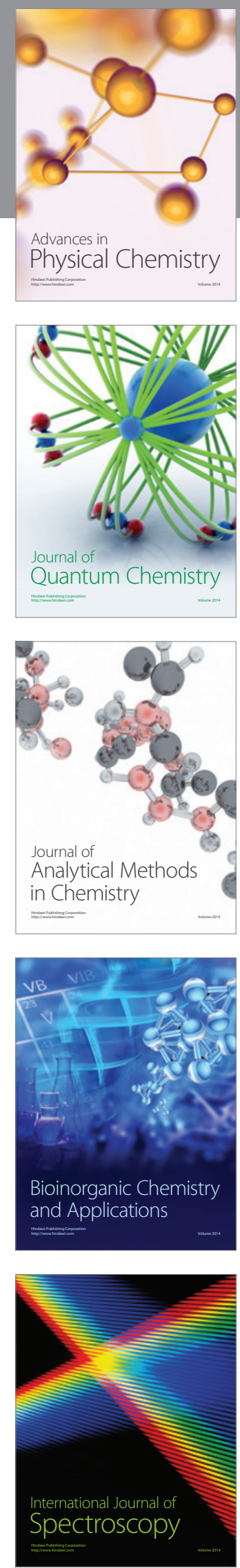